\title{
Histórico da implementação da algaroba no Rio Grande do Norte
}

\author{
João Paulo Silva dos Santos ${ }^{1 *}$, Marco Antonio Diodato ${ }^{2}$ \\ ${ }^{1}$ Universidade do Estado do Rio Grande do Norte, Rua Professor Antônio Campos, s/n, BR 110,Km 48, CEP 59600-000, Mossoró, RN, Brasil \\ ${ }^{2}$ Universidade Federal Rural do Semi-Árido, Av. Francisco Mota, n 572, CEP 59625-900, Mossoró, RN, Brasil
}

“Autor correspondente:
joaozxz@yahoo.com.br

Termos para indexação:

Prosopis juliflora

Zonas semiáridas

Espécies introduzidas

Index terms:

Prosopis juliflora

Semiarid zones

Invasive species

Histórico do artigo:

Recebido em 14/02/2015

Aprovado em 05/06/2017

Publicado em 30/06/2017

doi: $10.4336 / 2017 . p f b .37 .90 .859$

\begin{abstract}
Resumo - A algaroba (Prosopis juliflora (Sw) D.C.) constituiu-se como uma ação bem sucedida de introdução de xerófilas na região seca do Nordeste, sendo seus frutos usados na alimentação animal e a madeira em estacas, lenha e carvão. A espécie foi introduzida na região em 1942, se alastrando em "baixios" no Rio Grande do Norte, Paraíba, Pernambuco, Bahia e Piauí. Esta revisão tem como objetivo elucidar como a algaroba foi introduzida no Rio Grande do Norte e entender como foi sua disseminação. Sua introdução no Estado ocorreu a partir da instalação de experimentos na Fazenda São Miguel, no município de Angicos. O entusiasmo de técnicos e pesquisadores facilitou a distribuição de vagens e mudas nas propriedades rurais e cidades do Estado, contando também com incentivos governamentais para produção, distribuição e plantio da espécie. Pretende-se com esse trabalho estabelecer considerações que sirvam de base histórica para estudos sobre essa espécie exótica e abordar aspectos sobre a condição atual da cultura no Nordeste brasileiro.
\end{abstract}

\section{History of mesquite introduction in Rio Grande do Norte State, Brazil}

\begin{abstract}
The mesquite (Prosopis juliflora (Sw) DC) was established as a successful action of xerophilous introduction in Brazilian Northeast dry region. Its fruits are used in animal feed and the wood may be used as piles, firewood and charcoal. The species was introduced in 1942, spreading in "low areas" in Rio Grande do Norte, Paraiba, Pernambuco, Bahia and Piauí States. This article aims to elucidate how mesquite was introduced in Rio Grande do Norte State and to understand how it was spread. It was first introduced in Rio Grande do Norte State by the introduction experiments installed at São Miguel farm in the municipality of Angicos. The enthusiasm of technicians and researchers promoted the distribution of pods and seedlings on farms and cities in the state. In addition, there were government incentives to production, distribution and planting the species. This work aims to establish considerations to be used as historical basis on studies about this species and to consider aspects regarding current situation of this culture in Brazilian Northeast.
\end{abstract}

\section{Introdução}

A algaroba (Prosopis juliflora (Sw) D.C.) constituiuse como uma ação bem sucedida quando o assunto é a introdução de plantas xerófilas na região seca do
Nordeste (Franco, 2008). A espécie nativa das terras áridas das Américas e da África foi introduzida na região semiárida nordestina, em 1942, no município de Serra Talhada, sertão de Pernambuco, com o objetivo de aumentar a disponibilidade de recursos naturais das 
áreas semiáridas, principalmente para alimentar animais e também para ser uma alternativa de reflorestamento em áreas desmatadas do bioma Caatinga (Silva, 1989).

Atualmente, a árvore do gênero Prosopis é aproveitada no semiárido nordestino de três formas: na exploração da madeira para a produção de estacas e mourões e para fins energéticos, na forma de lenha e carvão; na alimentação dos rebanhos de ovinos, caprinos, bovinos, equinos e muares, por meio dos seus frutos; e para sombreamento, geralmente nas proximidades das casas sedes das fazendas, paralelo às cercas e em estradas das propriedades (Gomes, 1987; Mendes, 1987; Franco, 2010; Rodrigues et al., 2013).

Segundo Muniz (2009), a madeira e os frutos da algaroba podem ser de grande valia para o homem do campo das terras semiáridas, se forem aplicados processos mais aprimorados de aproveitamento. No entanto, é importante que as pessoas que se engajarem em iniciativas de introdução dos produtos advindos da algaroba na cadeia produtiva da região tenham disponível amparo técnico e econômico, por parte das instituições de pesquisa e financeiras.

As principais alternativas que podem ser desenvolvidas com o uso dos recursos da algaroba são o processamento da vagem para dar origem a produtos como pães, bolos, sorvetes, mel, bebidas, biocombustíveis e polissacarídeos (Baião, 1987; Muniz, 2009; Nascimento, 2011; Sousa Filho et al., 2013) e o beneficiamento da madeira da espécie que pode ser transformada em móveis, esquadrias e peças de madeira compactada (Mendes, 1986; Nascimento \& Lahr, 2007).

No entanto, a discussão sobre a presença da algaroba no semiárido nordestino não engloba somente discursos sobre as suas vantagens a as melhores formas de aproveitamento dos seus recursos, já que existem muitas considerações negativas relacionadas à espécie. Entre elas, as mais comuns são a invasão biológica sobre a vegetação típica da Caatinga (Pegado et al., 2006; Vilar, 2006), as doenças do "mau-da-cara-torta" e da "línguade-pau" verificadas em bovinos, caprinos e ovinos e a controversa questão sobre o grande consumo de água pela espécie, que para alguns autores ocasiona a redução da quantidade de água no solo (Gomes \& Barbosa, 2008).

$\mathrm{Na}$ Caatinga, a espécie vem se alastrando, principalmente, em áreas de "baixios" nos estados do Rio Grande do Norte, Paraíba, Pernambuco, Bahia e Piauí, formando grandes concentrações de indivíduos (Reis, 1985). Isto mostra que $P$. juliflora encontra-se extremamente confortável e estabilizada na região semiárida Nordestina (Lima et al., 2002). Alguns estudos discutem a necessidade de implementação de manejo adequado da algaroba, visando a contenção de sua proliferação e o aproveitamento de suas potencialidades, pois a espécie pode comprometer a sobrevivência de espécies nativas da Caatinga (Lima et al., 2002; Pegado et al., 2006; Oliveira, 2006; Vilar, 2006; Franco, 2008).

Nesse sentido, Pasiecznik (2002) descreve que a erradicação da algaroba é extremamente complexa, sendo necessário realizar uma exploração adequada dos recursos da espécie e executar ações de manejo corretas, que tenham como objetivo o controle populacional e que busquem preservar o patrimônio genético da Caatinga (Oliveira, 2006). As ações de controle que interrompam o processo de avanço da algaroba na Caatinga envolvem a poda das árvores, capina, coleta das vagens maduras e cerco das áreas onde exista a espécie, para evitar que os animais de pastejo se alimentem indiscriminadamente das vagens, oferecendo a eles apenas a vagem triturada nos cochos (Pasiecznik et al., 2001).

A discussão sobre benefícios e malefícios da algaroba, no Nordeste, é ampla e envolve várias áreas da ciência. Nesse sentido, o estudo sobre o histórico da sua introdução na área semiárida e sobre as suas formas de dispersão nos Estados que compõem a região é justificável, já que ela é uma espécie que oferece recursos importantes para as populações da região semiárida brasileira.

Essa revisão tem por objetivo elucidar como a algaroba foi introduzida no Rio Grande do Norte e entender, analisar e discutir como ela tornou-se tão presente na área rural e urbana em vários municípios do Estado.

\section{Introdução e dispersão da algaroba no semiárido nordestino}

No Nordeste Brasileiro, a algaroba foi introduzida primeiramente na região de Serra Talhada, Pernambuco, em 1942, com sementes procedentes da região de Piura, no Peru (Lima, 1984). Posteriormente, outras introduções foram realizadas, no Rio Grande do Norte, em 1946, por meio de sementes oriundas do Peru e, em 1948, no município de Angicos, com sementes do Sudão (Mendes, 1987). A partir desse momento, por intermédio da Secção do Fomento Agrícola Federal, ela foi introduzida no Ceará, em 1954, na região do Cariri, e passou a ser plantada na cidade de Sobral em 
1958 (Gomes, 1987). Na Paraíba, ela foi introduzida, primeiramente, na cidade de Serra Branca (Franco, 2008).

A partir dessas primeiras experiências, a algaroba foi disseminada de modo amplo em todas as áreas semiáridas do Nordeste e essa ação ocorreu em três fases principais. A primeira delas, entre os anos 1942 até 1960, foi o momento em que a espécie passou a despertar a curiosidade de técnicos e produtores rurais da região, culminando no seu plantio em algumas regiões. $\mathrm{O}$ interesse pela espécie se deu por sua fácil adaptação ao semiárido brasileiro e por sua alta capacidade forrageira durante a época que não chove no sertão, período com poucas opções de alimento para os animais. Segundo Silva (2000), existiu forte investimento por parte dos órgãos governamentais com o intuito de distribuir mudas entre os proprietários rurais e também de disseminar o conhecimento sobre a exploração dos recursos da espécie. Nesse período, estima-se que foram distribuídas cerca de dez milhões de mudas de algaroba nos estados do Rio Grande do Norte, Piauí, Ceará, Paraíba e Pernambuco (Gomes \& Barbosa, 2008).

Em 1959, o então Presidente do Brasil, Juscelino Kubitscheck, considerando a necessidade de um programa de desenvolvimento econômico que melhorasse as condições do nível de vida das populações nordestinas, promulgou o Decreto $\mathrm{n}^{\circ} 46.363$ (Brasil, 1959). O documento dispõe sobre as medidas necessárias e outras providências relacionadas ao desenvolvimento do cultivo de forrageiras no Nordeste, especialmente a algaroba. No Art. $2^{\circ}$ desse documento está definido que os trabalhos resultantes das providências descritas no decreto deveriam ser efetivados com o fornecimento de mudas, o oferecimento de assistência técnica e crédito rural. No Art. $4^{\circ}$ foram estabelecidos os órgãos da Autarquia Federal que deveriam cooperar com o Departamento Nacional de Produção Animal (DNPA). Estes eram o Departamento Nacional de Obras Contra as Secas (DNOCS), os Bancos do Nordeste do Brasil S.A(BNB), do Brasil (BB) e o Departamento de Serviço Florestal (DSF) (Brasil, 1959). Dessa forma, a política de incentivo ao plantio dessa espécie ganhou força e continuou a ser implementada no Nordeste.

Entre os anos de 1961 e 1965, se caracteriza a segunda fase. Nessa etapa, o então ministro da agricultura, Costa Porto, aprovou um significativo programa de plantio de algaroba no Nordeste. Dessa forma, em um semestre, seis milhões de mudas foram produzidas e, destas, três milhões e meio foram distribuídas e plantadas no semiárido. Porém, essa fase foi marcada pela falta de continuidade e sincronia das ações políticas voltadas para a agricultura (Cunha \& Silva, 2012).

Após a renúncia do então presidente Jânio Quadros, em 1961, o programa para o fomento da algaroba entrou em total declínio, sendo praticamente extinto. Durante essa fase, entre os estados do Nordeste, apenas na Paraíba restaram atividades voltadas para o plantio e aproveitamento de algarobeiras e seus frutos, localizadas, principalmente, no Cariri paraibano (Gomes \& Barbosa, 2008).

Após 1966, iniciou-se a terceira etapa, onde investimentos foram realizados em pesquisas e desenvolvimento de melhoramento da cultura para a implantação massiva em várias regiões do Nordeste. Nesse momento, foram realizadas ações de programas federais, estaduais e municipais para incentivar o uso dos recursos da algaroba e realizar plantios nas propriedades rurais e também em cidades, com fins de arborização (Gomes \& Barbosa, 2008).

Nessa fase, o Departamento Nacional de Obras Contra as Secas (DNOCS), na figura do Engenheiro Agrônomo Antônio Quirino Alves, recomendou e incentivou uma campanha para plantação, em larga escala, de algarobeiras no Cariri, nas áreas de Sertão e no Seridó do semiárido. O objetivo era que essa exótica, por meio de reflorestamento de áreas sem cobertura vegetal, executasse as funções de conservação do solo e de formação de pastos arbóreos tolerantes à pequena quantidade de chuva. Dessa forma, foram organizados eventos para a divulgação de trabalhos técnicos sobre a espécie, com o objetivo de socializar as descobertas e características da algaroba e incentivar o seu plantio. No entanto, essa fase não se deu de forma contínua e vários programas não atingiram o seu objetivo final (Cunha \& Silva, 2012).

A ideia de que a algaroba era a salvação do Nordeste, preconizada por diversos atores sociais, tais como políticos, elites agrárias, gestores públicos, técnicos e pesquisadores, acompanhou todas as fases dos programas de implantação da espécie. Esse apelo foi a principal causa que determinou o apoio das camadas sociais mais influentes da região, política e economicamente, que estavam inseridas no contexto das políticas de desenvolvimento da época. Na Paraíba, esse discurso foi de grande intensidade nas associações rurais dos municípios de Aroeiras, Cabaceiras, Campina Grande, 
Cubati, Juazeirinho, Monteiro, São João do Cariri, Serra Branca, Soledade, Sumé e Taperoá (Cunha \& Silva, 2012). Alguns agricultores dessas localidades redigiram documentos e os enviaram às autoridades brasileiras, exaltando as qualidades da espécie. Eles destacaram características como a grande resistência à seca e à salinidade, o desenvolvimento rápido e a produção de vagens, mesmo em período de seca, legitimando dessa maneira, o discurso de que a espécie seria a salvação para o Cariri e o Sertão paraibano (Gomes \& Barbosa, 2008).

Cunha \& Silva (2012) descrevem que a grande proporção da seca que atingiu a região na década de 1970 também contribuiu para a disseminação da algaroba no Nordeste. Naquele momento histórico, diversos programas foram executados, voltados ao desenvolvimento da agropecuária das regiões assoladas com a falta de água, promovendo crédito e assistência técnica aos produtores rurais. Os autores destacam que as principais ações desenvolvidas naquela época foram as implementações de programas governamentais, como o de Redistribuição de Terra e de Estímulo à Agroindústria do Norte e Nordeste (PROTERRA), o Programa de Desenvolvimento de Terras Integradas do Nordeste (POLONORDESTE) e o Programa Especial de Apoio ao Desenvolvimento da Região Semi-Árida do Nordeste (Projeto Sertanejo). Esse último, de início, deveria atender as populações mais pobres da região, mas seu foco foi redefinido para executar ações nas propriedades entre 20 e 500 ha. O Projeto Sertanejo visava permitir aos proprietários a obtenção de empréstimos nos bancos oficiais para financiamento de obras de açudes, currais, armazéns e para melhoria das culturas e dos rebanhos. Além disso, o Projeto Sertanejo também financiou o plantio de algarobeiras (Cunha \& Silva, 2012).

A implementação desses projetos, mesmo enfrentando dificuldades, delineou no semiárido um ambiente favorável à adoção de estratégias de inovação agrícola para o desenvolvimento. É a partir desse quadro que o Instituto Brasileiro de Desenvolvimento Florestal (IBDF) e a Superintendência do Desenvolvimento Econômico do Nordeste (SUDENE) iniciam o financiamento do plantio de algaroba no semiárido nordestino com ações voltadas para o reflorestamento. A espécie, dentro desse contexto, estava inserida na linha de estratégia do fortalecimento da economia nas unidades agropecuárias pequenas e médias, como uma alternativa para tornar as propriedades mais resistentes aos efeitos negativos da estiagem (Cunha \& Silva, 2012).

Assim, o IBDF, deu início, na década 1980, a um programa de reflorestamento grandioso. $\mathrm{O}$ órgão passou a financiar, de forma prioritária, grandes proprietários rurais, por meio de um planejamento de 20 anos onde no oitavo, previa-se o primeiro corte nas áreas plantadas. O objetivo maior dos incentivos fiscais ao reflorestamento era interligar a produção dessa ação à economia e proporcionar à população benefícios sociais, como empregos e a melhoria da qualidade de vida nas áreas rurais.

Dessa forma, nos estados da Bahia, Piauí e no norte de Minas Gerais, a prioridade foi dada ao plantio de pinus e de eucalipto. Para regiões litorâneas do Ceará, Pernambuco e do Rio Grande do Norte, foi implementado o plantio de espécies frutíferas, como caju e coco. Nas áreas semiáridas o reflorestamento foi realizado utilizando-se espécies xerófilas, como a algaroba (Cunha \& Silva, 2012). Sobre a política de plantios do IBDF, entre 1980 e 1982, Reis (1985) afirma que a área total com plantio de algaroba atingiu cerca de 52 mil ha nas áreas semiáridas do Nordeste.

Muniz (2009) afirma que em 1984, com incentivo de instituições públicas como o IBDF, a SUDENE, as Secretarias de Agricultura e as Empresas de Assistência Técnica e Extensão Rural dos Estados (EMATER's), foram implantados, aproximadamente, 90 mil ha de $P$. juliflora, em grandes áreas da Paraíba, Pernambuco e Rio Grande do Norte (Reis, 1985).

Ainda em 1984, surgiu outro programa do Ministério da Agricultura, visando ocupar 60 mil ha de algaroba na região Nordeste, chamado de "Projeto Algaroba". Esse foi financiado com recursos do Fundo de Investimento Social (FINSOCIAL), sem necessidade de retorno, por meio do Programa de Apoio ao Pequeno Produtor (PAPP) e coordenado pela Secretaria Nacional de Produção Agropecuária (SNAP), ligada ao Ministério da Agricultura (Reis, 1985).

Segundo Silva (1989) o Projeto Algaroba atendeu 8,3 mil pequenos produtores rurais na implantação de 18,8 mil ha em 540 municípios na área de atuação da SUDENE.

Paralelo a essas ações, a Embrapa realizou trabalhos de composição de um banco ativo de germoplasma que objetivava o melhoramento da algaroba. Para isso realizou estudos com diversas espécies do gênero 
Prosopis oriundas da Argentina, Chile, Peru, México, Estados Unidos, Honduras, Paquistão, Cabo Verde e Senegal (Lima, 1998). Esse projeto visava obter culturas de algaroba mais adaptadas às condições ambientais do Nordeste, cujos resultados não foram aplicados, permanecendo o trabalho limitado apenas à sua publicação.

Franco (2008) afirma que após esse período, as divulgações das pesquisas realizadas sobre o aproveitamento dos recursos da algaroba foram perdendo força com o passar dos anos e as informações sobre a utilização correta da espécie, no meio rural, foram ficando escassas até quase desaparecerem. Contudo, as pesquisas sobre as características dos recursos da espécie e suas formas de aproveitamento continuaram sendo realizadas, principalmente nas universidades (Pinheiro et al., 1987; Silva et al., 2002; Ribaski et al., 2009; Gonçalves et al., 2013).

Em 2005, o então Senador da República Ney Suassuna realizou um protesto em plenário enfocando a problemática sobre o "milagre da algaroba" na Paraíba. Para ele, por mais de 20 anos os agricultores do Estado foram enganados pelo então IBDF, atualmente Instituto Brasileiro do Meio Ambiente e dos Recursos Naturais (IBAMA). Essa afirmação teve como base o fato de que os produtores rurais que se interessaram em realizar o plantio da algaroba deveriam fazer um investimento inicial e plantar a cultura. Após isso, eles receberiam a visita de um técnico do IBDF, para a verificação da execução do plantio e, assim, efetuar a liberação da primeira parcela do programa, que foi paga. No entanto, as demais parcelas do incentivo ao reflorestamento, após mais de 20 anos, não chegaram aos produtores (Agência Senado, 2004).

Assim, a espécie que foi introduzida para ser de grande valia socioeconômica para a porção semiárida do Nordeste passou a ter um papel secundário na região. A partir disso, a algaroba encontrou condições propícias para se propagar, principalmente nas áreas antropizadas, às margens de corpos d'água. Com poucos predadores e sem nenhum controle, a espécie espalhou-se rapidamente (Franco, 2008). De fato, a espécie encontrou condições ambientais propícias ao seu desenvolvimento, mas também, a partir desse momento, o decréscimo e, finalmente, a ausência de interesse por essa espécie por parte dos órgãos pertinentes, contribuindo, provavelmente, para a sua dispersão descontrolada.

\section{Introdução e dispersão da algaroba no Rio Grande do Norte}

Paralelamente ao entusiasmo que a espécie provocava na região semiárida brasileira, o botânico S. C. Harland, empregado da empresa Cia. Brasileira de Linha para Coser (Machine Cotton), na fazenda São Miguel, em Angicos, depois de passar pelo Peru e de impressionarse com a algaroba, recomendou à administração do empreendimento o plantio de árvores forrageiras resistentes à seca, entre elas a algaroba, chegando, inclusive, a enviar em 1947 as primeiras sementes de algaroba para o Rio Grande do Norte, proveniente do deserto de Piura, no Peru). Também, em 1948 a empresa trouxe para a fazenda sementes originárias do antigo Sudão Anglo-Egípcio (Azevedo, 1987).

Dessa forma, das primeiras sementes que chegaram até o Rio Grande do Norte, resultaram em apenas quatro indivíduos arbóreos, que ficaram aos cuidados de um dos técnicos da fazenda, o geneticista Carlos Farias (Azevedo, 1987). Segundo Silva (1989) as plantas apresentavam aspectos diferenciados. As com espinhos longos e fortes e com porte baixo eram resultado da germinação das sementes do Sudão. As altas e com pequenos espinhos eram provenientes das sementes peruanas. Seguindo a recomendação do botânico inglês, a fazenda iniciou o cultivo da planta em terrenos de várzea e também nos tabuleiros rasos e pedregosos (Azevedo, 1987). Atualmente, ambas encontram-se amplamente disseminadas pelo Rio Grande do Norte.

Em uma das suas obras, Azevedo (1987) relata que a característica da algaroba de não perder as folhas no período de estiagem no semiárido lhe chamou a atenção. $\mathrm{O}$ autor obteve acesso às algarobas da fazenda São Miguel e também ao relatório em que S. C. Harland indicava a introdução da espécie como uma opção forrageira. Após verificar as características da espécie e resgatar informações sobre ela, Guilherme de Azevedo iniciou, de maneira informal, diversos experimentos com a algaroba no Rio Grande do Norte, procurando observar seu comportamento nas diversas áreas ecológicas e nos variados tipos de solo do Estado. De forma geral, o pesquisador identificou resultados animadores em relação à velocidade de crescimento da árvore, que chegou a $1 \mathrm{~m}$ ano $^{-1}$. Segundo Azevedo (1987), o comportamento da algaroba nas zonas semiáridas do Rio Grande do Norte, nos solos ricos e pobres, promovia esperança para a região. 
Outro entusiasta da algaroba estudou as árvores implementadas na fazenda São Miguel e também verificou um desenvolvimento animador, pois mesmo crescendo em solos pobres e em uma região com um, clima pouco chuvoso, as algarobas começaram a frutificar após o terceiro ano do plantio (Gomes, 1987). A partir de então, o entusiasmo de técnicos e fazendeiros em relação à algaroba cresceu e favoreceu as iniciativas de distribuição de mudas, principalmente nos municípios da região semiárida do Rio Grande do Norte.

Esse processo também incentivou estudos, como os realizados na então Estação Experimental do Seridó, sob o comando do agrônomo Fernando Melo, entre 1953 e 1955. Foram realizados experimentos com plantios de algaroba em 1953, visando obter informações sobre a produção da espécie e a germinação de suas sementes. Foram medidas as produções das árvores no período de um ano, o que animou os técnicos em relação ao potencial forrageiro da algaroba para o Rio Grande do Norte. Em 1958 na Fazenda Califórnia, no município de Macaíba, foi verificada uma produção média esperada para cada indivíduo em torno de $15 \mathrm{~kg}$ ano ${ }^{-1}$ (Azevedo, 1987).

A seca de 1958 também possibilitou nova avaliação do comportamento da espécie. A estiagem serviu para que os técnicos verificassem a resistência real da algarobeira a períodos sem chuva no semiárido. Naquele ano, o total de precipitação registrado na fazenda São Miguel foi de apenas $121 \mathrm{~mm}$, mas mesmo assim a espécie permaneceu verde e produzindo vagens (Azevedo, 1987). No entanto, o autor não fornece informações sobre a quantidade produzida, mas comenta que a avaliação indicou que a espécie era realmente adequada para a região, pois mantinha-se verde e produzindo mesmo com altas restrições hídricas.

Em uma das suas obras, Azevedo (1987, p. 14) demonstra o entusiasmo com relação à algaroba quando diz que:

Para as zonas secas do Rio Grande do Norte, onde tudo seca e desaparece na estiagem, seria uma verdadeira dádiva dos céus, se a algaroba ocupasse os tabuleiros e carrascos, fornecendo aos rebanhos forragem verde pelos seus ramos, e forragem concentrada pelos frutos.

Em 1960, o então professor da Universidade do Rio Grande do Norte e da Escola Agro-Técnica de Jundaí, Guilherme de Azevedo, realizou a primeira publicação em língua portuguesa relacionada à algaroba, o que demonstrou o grande interesse dos técnicos

Pesq. flor. bras., Colombo, v. 37, n. 90, p. 201-212, abr.jun. 2017 do Estado por essa espécie. Editada pelo Serviço de Informação Agrícola (SIA), órgão ligado ao Ministério da Agricultura, a obra foi resultado da visita do autor a alguns países da América Latina, como o Peru e a Argentina, para verificar as condições dos ambientes nativos da algaroba. Além disso, ele também realizou experimentos para verificar a quantidade produzida e a qualidade das vagens, assim como o potencial da espécie para reflorestamento das áreas semiáridas (Azevedo, 1960).

O conteúdo da publicação do Agrônomo enfocava basicamente algumas características da algaroba e da sua vagem e como ela poderia ser aproveitada nas regiões semiáridas do Brasil, trazendo dados sobre o manejo da espécie, a sua relação com atividades como a apicultura e a arborização de cidades. Além disso, nessa publicação também já existiam tópicos que desassociavam os frutos da espécie aos problemas que estavam sendo relacionadas a ela no Nordeste do Brasil, como a invasão biológica de áreas da Caatinga e as perturbações causadas nos animais pela ingestão das vagens (Azevedo, 1960), evidenciando a posição do autor a favor do plantio e uso da espécie.

No prefácio da segunda edição da obra, o diretor do Serviço de Informação Agrícola (SIA), José A. Vieira, relata o seguinte pensamento sobre o trabalho de Azevedo (1987, p. 6):

"Tratando-se do primeiro trabalho sobre o assunto [...] tem o SIA a certeza de, com tal publicação, proporcionar dados para a solução dos magnos problemas do reflorestamento e alimentação animal no Nordeste do Brasil".

Sobre o reflorestamento das terras desnudas do Rio Grande do Norte, balizados nos estudos e nas verificações da rusticidade hídrica da espécie, foi adotado o discurso que a algaroba seria uma alternativa de sucesso para as áreas semiáridas do Estado. Isso pode ser visualizado no trabalho de Azevedo (1987, p. 17):

É preciso reflorestar os sertões potiguares, mas torna-se necessário fazê-lo de modo bem orientado, para evitar resultados negativos. A algaroba surge como uma planta providencial num trabalho de reflorestamento. Resistente às secas, crescimento rápido, fácil fixação e possuidora de ótima madeira para lenha, fabricação de móveis, esquadrias, carvão, tacos e, até mesmo, dormentes.

Dessa forma, na década de 1960, apoiados pelo decreto presidencial de 1959, que discorria sobre o incentivo ao 
cultivo de algarobeiras no Nordeste, em sintonia com o que ocorria em outros estados do Nordeste, alguns órgãos federais relacionados à agricultura presentes no Rio Grande do Norte também realizaram várias ações de distribuição de mudas e de disseminação de informações sobre as utilidades da árvore, entre agricultores e fazendeiros. Nessa fase, destacaram-se os órgãos que integraram no Estado a coordenação estabelecida no decreto 46.363 de 1957, que foram a Inspetoria de Fomento Agrícola, o Serviço Florestal e Secretaria de Agricultura do Estado, a Associação Nordestina de Crédito e Assistência Rural e o Serviço de Assistência Rural da Arquidiocese de Natal (Gomes, 1987).

Sobre a espécie no Rio Grande do Norte, Azevedo (1987) destacou que a algarobeira vegeta bem em diversos tipos de solos do Estado. Para o autor ela cresce de forma considerável em áreas de aluviões, nos tabuleiros pedregosos e também nas dunas das áreas litorâneas.

Em experimentos realizados em 1960 e orientados pelo Serviço de Acôrdo de Fomento da Produção Animal (SAI), foi identificado que nos locais onde existiu uma alta precipitação pluviométrica, nos municípios de Goianinha e Macaíba, o crescimento foi prejudicado pela umidade do solo excessiva. No entanto, nas zonas secas do Seridó, nos municípios de Cruzeta e Caicó, as algarobas cresceram de forma impressionante e iniciaram a produção de vagens com apenas dois anos de idade (Azevedo, 1987).

Portanto, seguindo essas informações, os órgãos governamentais, além de estimularem o plantio da algaroba nas propriedades rurais particularmente nas áreas desmatadas, também incentivaram o plantio nos aglomerados urbanos. Dessa forma, para Azevedo (1987), o homem do campo iria ter a sua curiosidade despertada ao amarrarem seus animais nos troncos das árvores e verificassem o valor da forrageira, de modo direto, quando os animais se alimentassem das vagens caídas e, provavelmente, levaria as sementes daquela árvore para plantar na sua propriedade, aumentando a disseminação da algaroba nas terras do sertão do Estado. Com essa ideia, o autor destaca a arborização de algumas cidades com algaroba na década de 1960, como em São Tomé, Mossoró, Nova Cruz, Santo Antônio e São Paulo do Potengi.

Nesse período, o Rio Grande do Norte tornou-se fornecedor de sementes da espécie para o DNOCS. Foram criados viveiros de mudas com o objetivo de distribuí-las em outros Estados do Nordeste e até para Goiás (Gomes, 1987).

$\mathrm{Na}$ década de 1970, semelhante ao que ocorreu em todo o Nordeste, as ações de dispersão da algaroba pelo Estado ocorreram por meio dos seguintes fatores: distribuição de mudas pelo IBDF e DNOCS; incentivo dos técnicos das instituições Estaduais; e aquisição de sementes da algaroba por fazendeiros e pequenos agricultores. Apoiados pelo Programa Especial de Apoio ao Desenvolvimento da Região Semi-Árida do Nordeste (Projeto Sertanejo), muitos proprietários de terra receberam financiamentos para realizarem o plantio de algaroba, já que ela estava inserida na estratégia do fortalecimento da economia agropecuária do Nordeste para diminuir os problemas ocasionados pela falta de chuvas (Cunha \& Silva, 2012).

Devido à grande seca vivenciada do Nordeste, entre os anos de 1979 e 1983, o Governo Federal resgatou informações positivas disseminadas no meio técnico sobre as potencialidades da algaroba para áreas áridas. Essa ação gerou um ambicioso projeto de reflorestamento das áreas semiáridas do País com a espécie. Assim, em 1985 foi criado o Projeto Algaroba, que tinha como objetivo produzir e distribuir mudas, prestar assistência técnica e dar apoio financeiro aos produtores das áreas de influência da SUDENE (Cunha \& Silva, 2012).

Para realizar esse projeto, o Governo utilizou recursos do Banco Nacional de Desenvolvimento Econômico e Social (BNDES) e passou a responsabilidade da coordenação do mesmo para a Secretaria Nacional de Produção Agropecuária (SNAP), ligada ao Ministério da Agricultura, com a participação das Secretarias de Agricultura dos Estados do Nordeste.

A meta inicial do projeto previa o plantio total de 1,5 milhões de ha e pretendia atingir cerca de $290 \mathrm{mil}$ produtores rurais. O projeto deveria perdurar até 1988. Após revisões, a ação foi aprovada de forma definitiva com o objetivo de plantar 60 mil ha e beneficiar cerca de 20 mil produtores rurais de pequeno porte (Galvão \& Lima, 1987).

Assim, com a intermediação da Empresa Agropecuária Estadual os proprietários rurais de várias regiões do Rio Grande do Norte, assim como de outros estados do Nordeste, receberam recursos do projeto, a fundo perdido, para reflorestarem áreas de suas propriedades com algaroba, objetivando o desenvolvimento da pecuária na região (Universidade Federal de Campina Grande, 2006). 
Simultaneamente aos preparativos para o lançamento do Projeto Algaroba, em 1982 a Empresa de Pesquisa Agropecuária do Rio Grande do Norte (EMPARN) organizou um simpósio brasileiro sobre algaroba. No evento, realizado em Natal, foram apresentados diversos trabalhos que tratavam das potencialidades da espécie para as áreas semiáridas (Azevedo, 1982; Silva et al., 1982; Souza \& Tenório, 1982). Em 1983, a EMPARN, sobre a presidência de Benedito Vasconcelos Mendes, criou a Estação Experimental de Terras Secas (EETS). A sede do centro de pesquisa foi instalada no município de Pedro Avelino e tinha como um dos seus objetivos desenvolver linhas de estudos e projetos com plantas xerófilas, nativas e exóticas, estando entre elas a algarobeira (Mendes, 1986).

Em 1986, foi realizado na então Escola Superior de Agricultura de Mossoró, com o apoio da EMPARN, o segundo simpósio brasileiro sobre a algaroba (Figueiredo, 1987). No mesmo ano, houve um encontro internacional sobre Prosopis na cidade de Recife. $\mathrm{Na}$ assembleia geral do evento, por meio de uma proposta lançada por Benedito Vasconcelos Mendes, foi criada a Associação Brasileira de Algaroba (ABA). Uma iniciativa importante da ABA, já em 1987, foi o lançamento de publicação periódica, chamada Revista da ABA. Nos volumes da revista eram apresentadas pesquisas científicas que discorriam sobre as possíveis utilidades da algaroba, características da espécie e métodos de manejo (Galvão \& Lima, 1987).

Em agosto de 1986, a International Prosopis Association (IPA) promoveu, em Recife, PE, a Segunda Conferência Internacional sobre Prosopis. Na ocasião, o Professor Dr. Benedito Vasconcelos Mendes, um dos entusiastas da algaroba no Rio Grande do Norte, fez parte da comissão científica do evento (International Conference on Prosopis, 1988). Após o evento, a Organização para a Alimentação e Agricultura das Nações Unidas (FAO) publicou um livro contendo os trabalhos apresentados na conferência. No prefácio da publicação, a organização explicita a importância dos estudos sobre o gênero Prosopis no mundo. No documento a FAO exprime o seu interesse ao descrever que pretendia continuar a patrocinar, com o apoio dos governos locais, reuniões e publicações científicas sobre pesquisas realizadas com espécies de Prosopis. Para a FAO, as espécies do gênero são importantes para o desenvolvimento de terras áridas e semiáridas pauperizadas, pois elas são reconhecidamente um recurso significativo para o bem-estar presente e futuro da humanidade, já que oferece um recurso contra a fome.

Após os grandes eventos que discutiram o gênero Prosopis, em 1988 o Projeto Algaroba chegou ao fim. O seu resultado final foi o plantio de aproximadamente 100 mil ha de algarobas no Nordeste brasileiro durante o período em que esteve ativo (Bacha, 1995).

A partir de meados dos anos 1990, as potencialidades da algaroba caíram no esquecimento do governo e atualmente o quadro é o mesmo. A visão da espécie como salvadora das populações das áreas semiáridas nordestinas transformou-se, provavelmente resultante de estudos científicos. Ela é vista, principalmente entre os técnicos, como uma espécie invasora da Caatinga. Essa condição pode ser notada ao se realizar buscas e leituras sobre os principais estudos desenvolvidos relacionados com a presença da algaroba no semiárido nordestino (Lins e Silva, 1997; Oliveira, 2006; Vilar, 2006; Franco, 2008; Andrade et al., 2010).

Em estudos pioneiros sobre a invasão biológica da algaroba no Nordeste, Lins \&Silva (1997) investigaram os aspectos envolvidos no avanço da espécie na região e a descreveram como invasora de áreas da Caatinga. $\mathrm{O}$ estudo, desenvolvido na região do Seridó do Rio Grande do Norte, avaliou o comportamento da algaroba com base nos aspectos relacionados ao aumento das populações. A partir dos resultados obtidos ficou caracterizado que a espécie é realmente invasora de áreas da Caatinga e que ela se encontra na fase de "facilitação", tendo como principais agentes facilitadores os rebanhos de animais caprinos e bovinos, que seriam vetores da algaroba nas terras semiáridas, pois eles realizam a dispersão de suas sementes através da ingestão das vagens e posterior excreção.

Em outro estudo sobre o assunto, Oliveira (2006) considera que as alterações na fitodiversidade de áreas onde existem povoamentos de algaroba nos estados do Rio Grande do Norte e Paraíba resultaram em um agrupamento distinto no que se refere à composição florística, à diversidade e à estrutura da vegetação. Assim, para o autor, a espécie apresenta-se como colonizadora da Caatinga, principalmente por meio da criação de animais de forma extensiva, facilitando a dispersão das sementes e o acesso da mesma a locais propícios para a sua propagação, como áreas desmatadas e locais com solos de aluvião.

Mas, em meio à discussão da invasão biológica da Caatinga, são inúmeros os trabalhos que tem como 
iniciativa demonstrar que os recursos da algaroba são de grande valia para a região semiárida, se aproveitados de forma adequada (Vendruscolo, 2005; Muniz, 2009). Além dos citados, vários trabalhos sobre o uso das potencialidades da algaroba foram desenvolvidos e publicados no Rio Grande do Norte.

Gomes (1987) evidencia que a vagem da algaroba foi utilizada como alimento no Nordeste Brasileiro na região do Cariri Velho, no Ceará, durante a seca de 1958. Na ocasião, a população utilizava a vagem verde como se fosse uma vagem de feijão.

Ainda como alimento humano, Rocha (1987) identificou que a farinha da vagem da algaroba era utilizada, no município de Nova Cruz, no preparo de cuscuz, bolos, biscoitos, frituras à milanesa, para engrossar sopas e em associação com o feijão e mel, substituindo à farinha de mandioca. Além disso, o mel obtido era consumido com farinha ou puro e também era usado para preparar cocadas e puxa-puxa. O mesmo autor identificou que um produto similar ao café poderia ser obtido por meio do processamento da vagem.

Destacando o uso da vagem na alimentação dos animais, Nobre (1982) desenvolveu um trabalho publicado pela EMPARN. Na ocasião, o autor identificou uma maior eficiência de produção de leite ao empregar a vagem em até $60 \%$ ao farelo de trigo na dieta de vacas em lactação. Da mesma forma, Silva et al. (1982), em trabalho publicado em um Simpósio Brasileiro de Algaroba, realizado em Natal, observaram um bom desempenho no ganho de peso de bovinos de corte em sistema de confinamento alimentados com dietas contendo até $100 \%$ de vagem de algaroba triturada, substituindo o farelo de trigo.

Visualizando as potencialidades da espécie para os recortes semiáridos do Nordeste, Pires \& Kageyama (1985), apoiados pelo IBDF, desenvolveram pesquisa sobre as perspectivas de melhoramento genético da algaroba e fizeram experimentos em Caicó, no Rio Grande do Norte, e em Soledade, na Paraíba.

A EMPARN, utilizando a algaroba, realizou trabalhos de recuperação de área salinizadas e degradadas por atividade como a indústria ceramista e a agricultura irrigada. Os resultados obtidos foram bons. Em uma área degradada pela atividade ceramista, utilizando um espaçamento de $2 \mathrm{~m}$ x $1 \mathrm{~m}$, obteve-se produção de 500 $\mathrm{m}^{3} \mathrm{ha}^{-1}$ de madeira após 10 anos. Em área salinizada, a algaroba foi à espécie que apresentou melhor crescimento. Nesse estudo, aos três anos um indivíduo apresentava 7,5 $\mathrm{m}$ de altura e 8,0 cm de DAP (diâmetro 1,30 $\mathrm{m}$ do solo). Nesse mesmo estudo, os técnicos observaram uma taxa de sobrevivência de $100 \%$ das mudas plantadas (Araújo, 2010). Buscando verificar a produção madeireira da algaroba, Nobre (1982), em mais um publicação da EMPARN, verificou que um plantio de algaroba pode render de 100 a $120 \mathrm{~m}^{3} \mathrm{ha}^{-1} \mathrm{ano}^{-1} \mathrm{em}$ cinco anos.

Em estudo sobre o uso da carnaubeira (Copernicia prunifera (Mill.) H. E. Moore) e da algarobeira em uma comunidade do Município de Carnaubais, na região do Vale do Açu, Rodrigues et al. (2013) identificaram que os recursos da algaroba são utilizados como forragem, combustível e aplicados na construção de cercas e casas. Muitos dos entrevistados na pesquisa consideraram que a madeira da algaroba é de boa qualidade, apresenta boa duração e é uma opção para ser usada como lenha e para ser transformada em carvão. Nesse estudo, utilizando o método de cálculo do índice de significado cultural (ISC) das plantas, os autores identificaram que, apesar da algaroba não ser nativa, ela apresenta um significado cultural semelhante à da carnaúba e superior a de outras espécies típicas da região, como o juazeiro (Ziziphus joazeiro Mart.), o jatobá (Hymenaea courbaril L.), a jurema preta (Mimosa hostilis Mart. Benth), a catingueira (Caesalpinia pyramidalis $\mathrm{Tu}$.) e o jucá (Libidibia ferrea (Mart. Ex. Tul.) L. P . Queiroz).

Desse modo, o alastramento da algaroba pelo Estado criou uma visão dualista sobre a espécie. A discussão sobre os benefícios de suas potencialidades contrasta com os estudos que demonstram o potencial invasor da árvore em áreas da caatinga. As potencialidades que se destacam referem-se às qualidades como forrageira, principalmente por frutificar no período que não chove na região, e pelo seu material lenhoso, propício para uso na matriz energética nordestina. Como ponto negativo, enfatiza-se o desequilíbrio ecológico provocado pela presença exclusiva da algaroba ao invés das espécies nativas da Caatinga, principalmente nas proximidades de corpos d'água.

Essa dualidade criou um paradoxo, pois a exploração da algaroba é permitida por lei, por ser espécie exótica, o que aparentemente facilitaria a erradicação da espécie. Contudo, acabou propiciando o seu cultivo, pois é uma opção legal e econômica viável, já que não precisa de plano de manejo para a sua exploração, caso que não acontece com o uso de espécies da Caatinga. 


\section{Considerações finais}

A partir dos registros históricos levantados, evidenciase que o primeiro fato envolvido na introdução da algaroba no Rio Grande do Norte foi o surgimento de experimentos e interações entre o empreendimento algodoeiro do município de Angicos e técnicos de outros países. Esse intercâmbio resultou na introdução da algaroba no Estado. A partir de então, o processo de disseminação da espécie para outras partes do Rio Grande do Norte pode ser entendido como o produto da soma de dois fatores principais e um secundário.

O primeiro desses foi o entusiasmo dos técnicos e pesquisadores, nas décadas de 1960 e 1970. Essa condição promoveu a distribuição das vagens e de mudas entre proprietários de terras do Estado e para prefeitos de cidades.

O segundo fator primário foi o vasto incentivo governamental que foi dado às ações de produção, distribuição e plantio da espécie durante as duas décadas. Devido a isso, as ações governamentais promoveram o plantio de vários hectares da espécie no Rio Grande do Norte e também passaram a financiar pesquisas que demonstravam as potencialidades dos recursos e exaltavam as vantagens do cultivo da algaroba.

Não menos importante, o fator secundário que também contribuiu para a disseminação da espécie nas terras potiguares foi o intercâmbio das vagens e sementes da árvore entre os agricultores. Essa ação propiciou um alastramento da espécie em áreas desmatadas próximas a corpos d'água e em áreas de solos de aluvião. Esse processo teve como agentes facilitadores os animais que se alimentavam das vagens da algaroba, pois as sementes da espécie, após serem expelidas do trato digestivo dos rebanhos, têm a sua dormência quebrada e encontram condições propícias para germinarem e crescerem.

Diante das constatações, é válido lembrar que estão presentes nesse estudo apenas alguns recortes temporais, encontrados nos registros da literatura, e que as iniciativas de introdução e disseminação citadas fazem parte de um conjunto de fatos históricos que necessitam ser resgatados para favorecerem o entendimento sobre as contribuições que a espécie pode oferecer para a socioeconomia das localidades onde é encontrada, assim como sobre os seus reais impactos positivos e negativos para o ambiente natural da região semiárida nordestina. Assim, as informações discutidas nesse artigo buscam contribuir para o entendimento das peculiaridades históricas envolvidas no processo de introdução dessa espécie exótica no Rio Grande do Norte. Dessa forma, a discussão poderá contribuir para o desenvolvimento de outros estudos sobre as características, as formas de aproveitamento dos recursos e o controle da dispersão essa espécie nas terras potiguares e na região semiárida do Nordeste.

\section{Referências}

Agência Senado. Ney Suassuna: reflorestamento com algaroba fracassou e agricultores perdem terras. Brasília, DF: Senado Federal, 2004. Disponível em: <http://www12.senado.gov.br/noticias/ materias/2004/05/06/ney-suassuna-reflorestamento-com-algarobafracassou-e-agricultores-perdem-terras $>$. Acesso em: 28 set. 2013.

Andrade, L. A. et al. Impactos da invasão de Prosopis juliflora (sw.) DC. (Fabaceae) sobre o estrato arbustivo-arbóreo em áreas de Caatinga no Estado da Paraíba, Brasil. Acta Scientiarum. Biological Sciences, v. 32, n. 3, p. 249-255, 2010. DOI: 10.4025/actascibiolsci. v32i3.4535.

Araújo, M. S. A. Manejo de espécies florestais para produção de madeira, forragem e restauração de áreas degradadas. Caicó: Emparn, 2010. 60 p.

Azevedo, C. F. Como e porque a algarobeira foi introduzida no Nordeste. In: SIMPÓSIO BRASILEIRO SOBRE ALGAROBA, 1., 1982, Natal. Anais... Natal: Emparn, 1982. p. 300-306.

Azevedo, G. Algaroba. 2. ed. Mossoró: ESAM, 1987. 34 p.

Azevedo, G. Algaroba. Rio de Janeiro: Serviço de Informação Agrícola, 1960. 34 p.

Bacha, C. J. Análise custo-benefício dos programas de incentivo ao reflorestamento no Brasil. 1995. 52 f. Relatório de Pesquisa apresentado na Escola Superior de Agricultura "Luiz de Queiroz", Universidade de São Paulo, Piracicaba.

Baião, V. B. Características químicas e nutricionais das sementes da Algaroba (Prosopis juliflora (Sw) D.C.). In: SIMPÓSIO BRASILEIRO SOBRE ALGAROBA, 2., 1987, Mossoró. Anais... Mossoró: Coleção Mossoroense, 1987. p. 19-124.

Brasil. Decreto $\mathbf{n}^{\mathbf{0}}$ 46.363, de 7 de janeiro de 1959. Medidas necessárias ao desenvolvimento do cultivo de forrageira, especialmente a algaroba no Nordeste. Disponível em: $<$ http:// www2.camara.leg.br/legin/fed/decret/1950-1959/decreto-46363-7julho-1959-385432-publicacaooriginal-1-pe.html>. Acesso em: 05 abr. 2014. Publicado originalmente no Diário Oficial da União, Rio de Janeiro, RJ, Seção I, p. 15.491, 9 jul. 1959.

Cunha, L. H. \& Silva, R. A. G. A trajetória da algaroba no semiárido nordestino: dilemas políticos e científicos. Raízes, v. 1, n. 32, p. 72-95, 2012.

Figueiredo, A. A. Industrialização das vagens de algaroba (Prosopis juliflora Sw Dc) visando a produção da goma da semente In: SIMPÓSIO BRASILEIRO SOBRE ALGAROBA, 2., 1987, Mossoró. Revista da Associação Brasileira de Algaroba, v. 1, n. 4, p. 7-34, 1987. 
Franco, E. S. et al. Viabilidade sócio-ambiental da algaroba no cariri paraibano. Engenharia Ambiental, v. 7, n. 4, p. 232-248, 2010.

Franco, E. S. Os discursos e contra-discursos sobre a algarobeira (Prosopis sp) no cariri paraibano. 2008. 86 f. Tese (Doutorado) Universidade Federal de Campina Grande, Campina Grande.

Galvão, A. P. M. \& Lima, P. C. F. Considerações sobre pesquisa com algaroba desenvolvidas pelo programa nacional de pesquisa florestal do Nordeste. Revista da Associação Brasileira da Algaroba, v. 1, n. 1, p. $111,1987$.

Gomes, P. A algarobeira. 2. ed. Rio de Janeiro: Serviço de Informação Agrícola, 1987. 49 p.

Gomes, R. \& Barbosa, A. G. A ecologia política da algaroba: uma análise das relações de poder e mudança ambiental no Cariri Ocidental - PB. In: REUNIÃO BRASILEIRA DE ANTROPOLOGIA, 26., 2008, Porto Seguro. Anais... Porto Seguro: ABA, 2008. p. 28-44. Disponível em: <http://www.abant.org.br/conteudo/ANAIS/CD_ Virtual_26_RBA/grupos_de_trabalho/trabalhos/GT 36/Ramonildes Gomes.pdf>. Acesso em: 21 jan. 2013.

Gonçalves, G. S. et al. Qualidade fisiológica de sementes de algaroba recuperadas de excrementos de muares. Semina: Ciências Agrárias, v. 34, n. 2, p. 593-662, 2013. DOI: 10.5433/1679-0359.2013v34n2p593.

International Conference on Prosopis, 2., 1986, Recife. The current state of Knowledge on Prosopis juliflora. Rome: FAO, 1988. Disponível em: $<$ http://www.fao.org/docrep/006/ad317e/AD317E01. $\mathrm{htm}>$. Acesso em: 26 maio 2014.

Lima, P. C. F. Algaroba, uma das alternativas do Nordeste. Brasil Florestal, n. 28, 1984.

Lima, P. C. F. Genetic improvement program of Prosopis in Northeastern Brazil. In: Puri, S. (Ed.). Tree improvement: applied research and technology transfer. Enfield: Science Publishers, 1998. p. 141-154.

Lima, P. C. F. et al. Regeneração natural em área degradada por mineração de cobre, no semi-árido brasileiro. In: CONGRESSO NACIONAL DE BOTÂNICA, 53., 2002, Recife. Anais... Recife: SSB, 2002. p. 377-378.

Lins e Silva, A. C. B. Characteristics of Prosopis juliflora invasion of semi-arid habitats in Norteast Brazil. 1997. $76 \mathrm{f}$. Thesis (Mater of Science) - University of Durham, Durham.

3.

Mendes, B. V. Alternativas tecnológicas para a agropecuária do semi-árido. São Paulo: Nobel, 1986. 171 p.

Mendes, B. V. Plantas e Animais Para o Nordeste. Rio de Janeiro: Globo, 1987. 167 p.

Muniz, M. B. Processamento das vagens de algaroba (Prosopis juliflora) para produção de bioprodutos. 2009. 179 f. Tese (Doutorado) - Universidade Federal de Campina Grande, Campina Grande.

Nascimento, C. E. S. Invasão da algarobeira: impactos positivos. Petrolina: Embrapa, 2011. Disponível em: <http://www.infoteca. cnptia.embrapa.br/bitstream/doc/926508/1/Clovisfolderalgarobadef. pdf $>$. Acesso em: 30 jul. 2013.
Nascimento, M. F. \& Lahr, F. A. R. Emprego da algaroba (Prosopolis juliflora) na produção de chapas de partículas homogêneas. Minerva, v. 4, n. 1, p. 51-56, 2007. Disponível em: <http://www.fipai.org.br/ Minerva\%2004(01)\%2006.pdf>. Acesso em: 05 maio 2013.

Nobre, F. V. Algaroba, importante forrageira para o Nordeste. 2. ed. Natal: EMPARN, 1982. 41 p.

Oliveira, F. X. Impactos da invasão da algaroba-Prosopis juliflora (Sw) DC. - sobre o componente arbustivo-arbóreo da caatinga nas microrregiões do Curimataú e do Seridó nos Estados da Paraíba e do Rio Grande do Norte. 2006. 138 f. Dissertação (Mestrado em Agronomia) - Universidade Federal da Paraíba, Areia.

Pasiecznik, N. M. et al. The Prosopis juliflora - Prosopis pallida Complex: a monograph. Coventry: Hdra, 2001. Disponível em: <http://r4d.dfid.gov.uk/PDF/Outputs/Forestry/R7295_Prosopis_ Monograph.pdf>. Acesso em: 09 out. 2013.

Pasiecznik, N. M. Prosopis juliflora (vilayati babul) in the drylands of India: develop this valuable resource: don't eradicate it. Coventry: Hdra, 2002. Disponível em: <http://gardenorganic.org.uk/sites/ www.gardenorganic.org.uk/files/resources/international/ProsopisPolicyBrief-2.pdf>. Acesso em: 16 set. 2013.

Pegado, C. M. A. et al. Efeitos da invasão biológica de algaroba Prosopis juliflora (Sw.) DC. sobre a composição e a estrutura do estrato arbustivo-arbóreo da caatinga no Município de Monteiro, PB, Brasil. Acta Botanica Brasilis, v. 20, n. 4, p. 887-898, 2006.

Pinheiro, M. J. P. et al. Utilização da vagem da algaroba [Prosopis Juliflora (SW) D. C.] na alimentação de suínos em terminação. Caatinga, v. 1, n. 8, p. 62-74, 1987.

Pires, I. E. \& Kageyama, P. Y. Caracterização da base genética de uma população de algaroba (Prosopis juliflores (SW) DC) existente na região de soledade-PB. IPEF, n. 30, p 29-36, 1985.

Reis, M. S. A política de reflorestamento para o Nordeste Semi-Árido. In: SEMINÁRIO SOBRE POTENCIALIDADE FLORESTAL DO SEMI-ÁRIDO BRASILEIRO, 1., 1985, João Pessoa. Anais... João Pessoa: Silvicultura, 1985. v. 37, p. 33-37.

Ribaski, J. et al. Algaroba (Prosopis juliflora): Árvore de Uso Múltiplo para a Região Semiárida Brasileira. Colombo: Embrapa, 2009.

Rocha, R. G. A. A algaroba na alimentação e farmacopeia do homem rural norte-riograndense. In: SIMPÓSIO BRASILEIRO SOBRE ALGAROBA, 2., Mossoró, Anais... Mossoró: Coleção Mossoroense, 1987. p. 61-65.

Rodrigues, L. C. et al. Conhecimento e uso da carnaúba e da algaroba em comunidades do Sertão do Rio Grande do Norte, Nordeste do Brasil. Revista Árvore, v. 37, n. 3, p. 451-457, 2013. DOI: 10.1590/ s0100-67622013000300008.

Silva, D. S. et al. Substituição do farelo de trigo (Triticum vulgare Komarnitzky) pelo fruto triturado da algarobeira (Prosopis juliflora (S.w) DC.) In: SIMPÓSIO BRASILEIRO SOBRE ALGAROBA, 1., Natal. Anais... Natal: EMPARN, 1982. p. 361-379.

Silva, J. H. V. et al. Uso da farinha integral da vagem de algaroba (Prosopis juliflora (Sw.) D.C.) na alimentação de codornas japonesas. Revista Brasileira de Zootecnia, v. 31, n. 4, p. 1789-1794, 2002. 
Silva, S. Algarobeira (Prosopis Juliflora (Sw) D. C) no Nordeste do Brasil. Brasília, DF: Ministério da Agricultura, Secretaria Nacional de Produção Agropecuária, Secretaria da Produção Animal, 1989. $74 \mathrm{p}$.

Silva, S. (Ed.) História da algarobeira no Brasil. Teresina: Embrapa Meio-Norte, 2000. 130 p.

Sousa Filho, M. de S. M. de et al. Extração e caracterização de galactomanana de vagens de algaroba (Prosopis juliflora). Fortaleza: Embrapa Agroindústria Tropical, 2013. 7 p. Disponível em: < http://ainfo.cnptia.embrapa.br/digital/bitstream/item/98633/1/ COT13007.pdf>. Acesso em: 03 nov. 2014.

Souza, R. F. \& Tenório, Z. Potencialidade da algaroba no Nordeste. In: SIMPÓSIO BRASILEIRO SOBRE ALGAROBA, 1982, Natal. Algaroba: conferências e trabalhos apresentados. Natal: EMPARN, 1982. v. 1.
Universidade Federal de Campina Grande. Projeto de pesquisa da UFCG sobre a algaroba é aprovado pelo CNPq. 2006. Disponível em: $<$ http://www.ufcg.edu.br/prt_ufcg/assessoria_imprensa/mostra noticia.php?codigo=2071>. Acesso em: 18 maio 2014 .

Vendruscolo, C. W. Goma xantana e galactomanana ( $\boldsymbol{m}$. Scabrella): desenvolvimento de matrizes hidrofilicas para liberação modificada de teofilina. 2005. 112 f. Dissertação (Mestrado) - Universidade do Vale do Itajaí, Itajaí.

Vilar, F. C. R. Impactos da invasão da algaroba [Prosopis juliflora (Sw.) DC.] sobre estrato herbáceo da caatinga: florística, fitossociologia e citogenética. 2006. Tese (Doutorado em Agronomia) - Universidade Federal da Paraíba, Areia. 